\title{
Sexual Dysfunction Among Patients with End-Stage Renal Disease Undergoing Hemodialysis: Prevalence and Associated Factors
}

\author{
Mansour Shakiba ${ }^{1}$, Nour-Mohammad Bakhshani (iD) ${ }^{2}$, Zohre Soorgi ${ }^{1,{ }^{*}}$ and Shahab Lotfinia (ii) ${ }^{3}$ \\ ${ }^{1}$ Department of Psychiatric, Zahedan University of Medical Science, Zahedan, Iran \\ ${ }^{2}$ Children and Adolescent Health Research Center, Zahedan University of Medical Sciences, Zahedan, Iran \\ ${ }^{3}$ Department of Clinical Psychology, Zahedan University of Medical Science, Zahedan, Iran \\ Corresponding author: : Department of Psychiatric, Campus of Zahedan University of Medical Sciences, Zahedan University of Medical Science, Zahedan, Iran. Tel: \\ +98-5433372151, Email: soorgizohre@gmail.com
}

Received 2019 November 10; Revised 2020 April 11; Accepted 2020 May 16

\begin{abstract}
Background: Chronic renal disease is a worldwide concern. The number of patients on hemodialysis increases every year. These patients have several physiological and psychological problems like sexual dysfunction that can affect their mental health and treatment course.

Objectives: This study first aimed to assess the prevalence of sexual dysfunction in end-stage renal disease (ESRD) patients on hemodialysis compared to healthy people. Then, it evaluated factors associated with sexual dysfunction in both groups.

Methods: This cross-sectional study recruited a total of 142 participants in two groups selected by a convenience sampling method. Group one included 71 ESRD patients from two hemodialysis centers in Zahedan, Southeast of Iran, recruited between September 2018 and September 2019. Group two included 71 healthy individuals matched for age, weight, and educational status. The two groups were assessed based on psychiatric interviews, the International Index of Erectile Function (IIEF), and the index of female sexual function (IFSF). The SPSS 24 software was used for data analysis. The bivariate Pearson correlation test, Cramer V, and independent-t-test were used to analyze the data.

Results: All female patients and $90 \%$ of healthy females had various levels of sexual dysfunction, and there was no significant difference between them $(\mathrm{P}=\mathbf{0 . 2 1})$. However, $84.6 \%$ of male patients and $33.3 \%$ of healthy males had various levels of sexual dysfunction and there was a significant difference between the two groups $(\mathrm{P}<0.001)$. The duration of hemodialysis was not correlated with sexual dysfunction. Age, weight, educational status, and marriage duration showed the most correlations with sexual dysfunction, especially in females.

Conclusions: As the findings showed, sexual dysfunction had a high prevalence among hemodialysis patients. As many of these patients must be on hemodialysis for long periods, we need to pay attention to sexual dysfunction when assessing and planning for their treatment.
\end{abstract}

Keywords: Erectile Dysfunction, Kidney Failure, Renal Dialysis, Sexuality

\section{Background}

Worldwide there is a shortage of kidney available for transplant, and the number of patients with end-stage renal disease (ESRD) is rapidly increasing. End-stage renal disease is the last stage of chronic renal disease in which the kidneys fail to work properly and become fatal unless using hemodialysis or renal replacement. Hemodialysis is the most common form of renal replacement, and around a million ESRD patients are on maintenance dialysis $(1,2)$. Hemodialysis can make several physiological and psychological changes (3).

End-stage renal disease exceedingly influences sexual health, mainly because of endocrine abnormalities. How- ever, sexual dysfunction (SD) may be formed by both physiological and psychological reasons, such as hormonal abnormalities, dysautonomia, vascular disease, drug-related adverse effects, and depression that are very prevalent in these patients (4-6). Furthermore, SD can lead to severe distress and interpersonal pressures (7). Besides, culture has shown to influence the presentation of SD. While sexual dysfunction is seen worldwide, the presenting symptoms may vary (8).

A large number of studies have focused on SD in men. Sexual dysfunction is highly prevalent in male ESRD patients undergoing hemodialysis. The most frequent issue studied has been erectile dysfunction (ED) (9). Several studies showed that phosphodiesterase-5 inhibitors 
could improve erectile dysfunction in men with ESRD (1012). In a comprehensive study of 302 communities of male hemodialysis patients, Rosas et al. found that $82 \%$ of patients had ED. Research by Turk et al. showed ED in 70\% of patients with chronic hemodialysis $(13,14)$. Older age and diabetes were correlated with ED in both of the studies. Considering different definitions and methods used in previous studies, the prevalence of ED has broadly ranged from 41 to $93 \%$ (15-17).

Sexual dysfunction in female ESRD patients is correlated with problems in biopsychosocial domains that lead to difficulties with sexual desire, arousal, vaginal lubrication, orgasm, and pain during intercourse. Despite that women comprise almost half of the hemodialysis patients, a few studies have focused on female SD; therefore, the understanding of this disorder is limited $(3,18,19)$. Yazici et al. (20) studied 117 women with ESRD and found that SD was present in $94 \%$ of the patients on peritoneal dialysis and $100 \%$ of those on hemodialysis. A report by Strippoli et al. (21) from 27 randomly selected dialysis units in Europe, and South America showed 84\% of females with SD based on the FSFI scores. Individual domains with the highest level of dysfunction were arousal, whereas satisfaction appeared to be the least impaired domain. Adjusted analyses showed that lower education levels, symptoms of depression, menopausal status, diabetes, low serum albumin, and diuretic therapy were independently correlated with a higher risk of SD (21). Despite the high prevalence of SD in the general population $(22,23)$ and ESRD patients, there are limited studies that compare SD between hemodialysis patients and healthy individuals.

\section{Objectives}

The first aim of this study was to assess the prevalence of sexual dysfunction in ESRD patients on hemodialysis compared to healthy people. The second aim was to evaluate the factors associated with sexual dysfunction in both groups.

\section{Methods}

\subsection{Procedure}

The current study included 142 participants. A convenience sampling method was used to employ all ESRD patients between September 2018 and September 2019 in two hemodialysis centers in Zahedan, Southeast of Iran, based on the inclusion criteria. The control group included 71 healthy individuals matched for age, weight, and educational status. All research procedures were approved by the Ethics Committee of Zahedan University of Medical Sciences (code: IR.ZAUMS.REC.1397.236). A complete history, including physical illnesses, psychiatric disorders, drug abuse, and sexual problems, was taken based on interviews, the International Index of Erectile Function (IIEF), and the index of female sexual function (IFSF). Informed consent was taken from all participants. The inclusion criteria included being a married person, age of 18 to 60 years, no physical or psychological condition that caused sexual dysfunction, no drug abuse, no recent infection, hemodialysis sessions at least twice a week for a minimum of three months (for the patient group), and no surgery that manipulated the genital system. The exclusion criteria included unwillingness to participate in the study and irregular attendance in hemodialysis sessions.

\subsection{Measurements}

The sociodemographic data included gender, age, weight, duration of hemodialysis, number of children, years of marriage, and educational status. The IFSF contained 19 items on a five-point Likert scale ranging from " 0 " to " 5 ". The IFSF assesses six domains of sexual function, including desire, arousal, lubrication, orgasm, satisfaction, and pain. The scores for each domain range between 0 or 1 and $5(19,21)$. The reliability of the IFSF Persian version was 0.70 measured by Cronbach's alpha coefficient and its validity was 0.73 based on the principal component analysis using varimax rotation, followed by confirmatory factor analysis $(24,25)$.

The IIEF contained 15 items on a five-point Likert scale ranging between 1 (almost never) and 5 (almost always). The index assesses five domains, including erectile function, with a maximum score of 30 . A higher score indicates a better sexual function (26). The test-retest reliability of the IIEF Persian version was 0.95 and its divergent validity evaluated by Spearman's rank correlation was 0.74 , which was acceptable (27).

\subsection{Statistical Analysis}

The patients' characteristics are presented as mean (SD) and frequency. The independent-t test was used to evaluate differences between the groups and compare sociodemographic data. The correlations of FSFI, IIEF, and their domains with demographic data were evaluated by the Bivariate Pearson correlation test. Cramer V was used to compare the educational status. The statistical significance level was set at $\alpha=0.05$ 


\section{Results}

\subsection{Demographic Data of Participants}

Of 71 participants in both groups, $32(45.1 \%)$ were female. Age $(\mathrm{t}=1.26, \mathrm{P}=0.20)$, weight $(\mathrm{t}=-1.86, \mathrm{P}=0.64)$, and educational status (Cramer's $\mathrm{V}=0.23, \mathrm{P}=0.07$ ) were the same in the two groups. The sociodemographic data are summarized in Table 1.

\begin{tabular}{|c|c|c|c|}
\hline Variables & $\begin{array}{c}\text { On Dialysis }(\mathrm{N}= \\
\mathbf{7 1})\end{array}$ & $\begin{array}{c}\text { No History of } \\
\text { Dialysis }(\mathbf{N}=71)\end{array}$ & P Value \\
\hline Age, $y$ & $43.66 \pm 9.17$ & $41.53 \pm 10.76$ & 0.207 \\
\hline Weight, kg & $64.84 \pm 10.83$ & $68.33 \pm 11.46$ & 0.64 \\
\hline $\begin{array}{l}\text { Duration of } \\
\text { hemodialysis, } \\
\text { mo }\end{array}$ & $25.88 \pm 30.08$ & - & \\
\hline Marriage years & $23.22 \pm 25$ & $17.26 \pm 19$ & 0.003 \\
\hline \multicolumn{4}{|l|}{ Gender } \\
\hline Female & $32(45.1)$ & $32(45.1)$ & \\
\hline Male & $39(54.9)$ & $39(54.9)$ & \\
\hline $\begin{array}{l}\text { Number of } \\
\text { Children }\end{array}$ & & & 0.001 \\
\hline None & $7(9.9)$ & $10(14.1)$ & \\
\hline $1-3$ & $23(32.4)$ & $46(64.8)$ & \\
\hline $4-6$ & $29(40.8)$ & $15(21.1)$ & \\
\hline$>7$ & $12(16.9)$ & $0(85.9)$ & \\
\hline Education status & & & 0.07 \\
\hline Illiterate & $16(22.5)$ & $9(12.7)$ & \\
\hline Elementary & $32(45.1)$ & $24(33.8)$ & \\
\hline Diploma & $16(22.5)$ & $24(33.8)$ & \\
\hline $\begin{array}{l}\text { Post- } \\
\text { secondary } \\
\text { school }\end{array}$ & $7(9.9)$ & $14(19.7)$ & \\
\hline
\end{tabular}

${ }^{\mathrm{a}}$ Values are expressed as No. (\%) or mean \pm SD.

\subsection{Prevalence of Sexual Dysfunction}

The results showed that $100 \%$ of women on dialysis and $90 \%$ of women with no history of dialysis had various levels of SD. While $84.6 \%$ of men on dialysis and $33.3 \%$ of men with no history of dialysis had various levels of ED (Figure 1). The mean and median scores of sexual function are summarized in Table 2.

\subsection{Differences Between the Groups}

The results of the independent $t$-test on sexual function showed significant differences in the total score of IIEF and the scores of all five domains between the two groups. The results of the independent $t$-test on sexual function showed no significant difference in the total score of IFSF and the scores of desire, arousal, satisfaction, and pain between the two groups (Table 2).

4.4. Correlation Between Sexual Dysfunction and Demographic Data

The results of the Bivariate Pearson correlation between demographic data and sexual dysfunction for both groups are summarized in Table 3.

\section{Discussion}

Sexuality is one of the most complex areas of human behavior. Sexual function can be affected by illnesses, psychological conditions, relationships, and many other factors. Chronic illness is usually related to SD because of malaise, fatigue, body image, hormone changes, and brain alternations. Previous studies showed that emotional issues could affect sexual function in the general population (28). Any mental or physical condition that could affect the quality of life also could affect sexual desire and function (19). However, in the current study, patients with psychiatric disorders or chronic disorders other than ESRD were excluded. Some authors advocate the use of physiological evaluations, but such results could not relate these measures to SD. Multidimensional self-report questionnaires like IIEF and FSFI are still the most widely used instruments in evaluating SD (29). In the current study, 142 subjects, including ESRD patients and healthy individuals, were assessed by self-report questionnaires. The results showed men on hemodialysis had significantly higher sexual dysfunction, but there was no difference in SD between women of the two groups, except in desire, arousal, satisfaction, and pain.

As the results showed, all ESRD women on hemodialysis and 90\% of healthy women had various levels of SD symptoms. The patients showed more dysfunction in desire, arousal, and satisfaction among the six domains of FSFI. However, healthy women showed more dysfunction in lubrication, satisfaction, and pain. This finding is in line with the results of a multinational study by Strippoli et al. (21) that assessed SD in the range of 55 to $96 \%$ in 1,472 ESRD patients. Yazici et al. (20) used a similar questionnaire as used in the current study and showed that all of the female hemodialysis patients $(n=117)$ and $45.8 \%$ in the control group $(n=48)$ had SD, which showed a lower prevalence of SD in healthy individuals than that shown by the current study. Other studies also showed that SD is present in higher than $78 \%$ of female ESRD patients (2, 30). Menopause can be a cause of SD with increasing age in women. It is reported that postmenopausal women have higher complaints such as reduced desire, lubrication difficulties, difficulty in achieving orgasm, vaginal dryness, 


\section{Female Patients with ESRD}

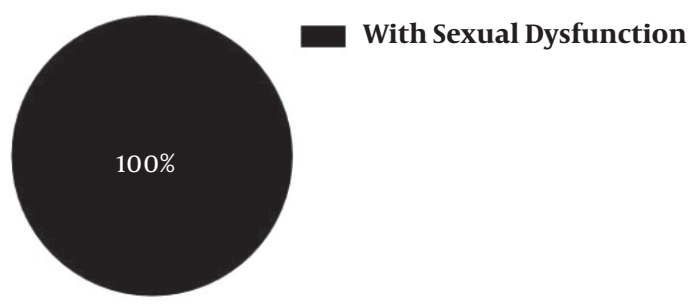

Male Patients with ESRD

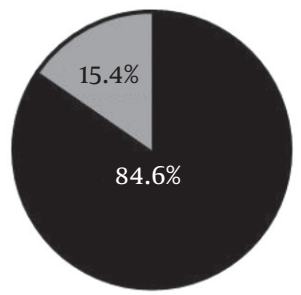

\section{Healthy Females}

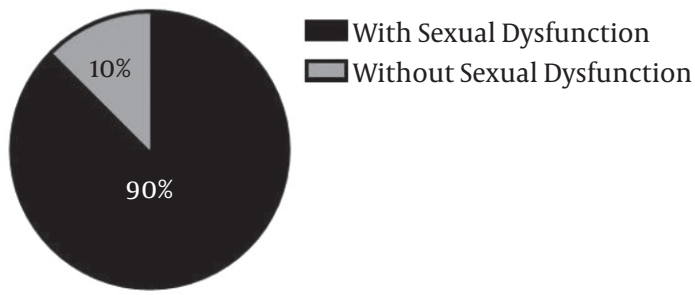

Healthy Males

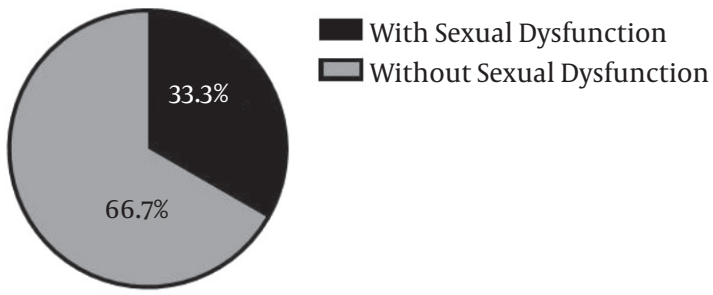

Figure 1. Prevalence of sexual dysfunction

Table 2. The Results of Independent-t-test Between Groups $(\mathrm{N}=142)^{\mathrm{a}}$

\begin{tabular}{|c|c|c|c|c|c|}
\hline Variables & Range & On Dialysis $(N=71)$ & No History of Dialysis $(N=71)$ & $t$ & P Value \\
\hline \multicolumn{6}{|l|}{ Males } \\
\hline Sexual desire & $1-10$ & $4.92 \pm 2.55$ & $8.02 \pm 1.76$ & -6.22 & 0.001 \\
\hline Erectile function & $1-30$ & $13.28 \pm 8.55$ & $23.97 \pm 9.37$ & -5.26 & 0.001 \\
\hline Orgasm satisfaction & $1-10$ & $4.10 \pm 2.98$ & $7.71 \pm 2.61$ & -5.69 & 0.001 \\
\hline Intercourse satisfaction & $1-15$ & $5.89 \pm 4.54$ & $11.46 \pm 3.83$ & -5.84 & 0.001 \\
\hline Overall satisfaction & $1-10$ & $4.48 \pm 2.79$ & $8.33 \pm 2.04$ & -6.93 & 0.001 \\
\hline Total score & $5-75$ & $32.69 \pm 20.19$ & $59.51 \pm 16.61$ & -6.40 & 0.001 \\
\hline \multicolumn{6}{|l|}{ Females } \\
\hline Desire & $1-5$ & $2.08 \pm 1.05$ & $3.22 \pm 1.76$ & -3.15 & 0.003 \\
\hline Arousal & $0-5$ & $1.81 \pm 1.4$ & $2.99 \pm 2.44$ & -2.35 & 0.02 \\
\hline Lubrication & $0-5$ & $2.32 \pm 1.80$ & $2.41 \pm 2.15$ & -0.19 & 0.85 \\
\hline Orgasm & $0-5$ & $2.06 \pm 1.61$ & $2.93 \pm 2.24$ & -1.78 & 0.07 \\
\hline Satisfaction & $1-5$ & $2.02 \pm 1.52$ & $2.93 \pm 1.78$ & -2.20 & 0.03 \\
\hline Pain & $0-5$ & $2.61 \pm 2.31$ & $1.35 \pm 2.11$ & 2.28 & 0.02 \\
\hline Total score & $2-36$ & $12.91 \pm 7.99$ & $15.85 \pm 10.47$ & -1.26 & 0.21 \\
\hline
\end{tabular}

${ }^{\mathrm{a}}$ Values are expressed as mean $\pm \mathrm{SD}$.

and pain (31). The researchers determined that the multifactorial causes of SD in ESRD patients include age, physiological status, psychological status, medical health, the experience of a sad event, menstruation status, type of dialysis, presence of a fistula, medication use, number of live childbirths, and the site of previous surgery (32). Based on the literature, the emotional state of women on dialysis can affect sexual function, as well (3).

The current study showed that $90 \%$ of healthy women had sexual dysfunction, and the rate of dysfunction in its 


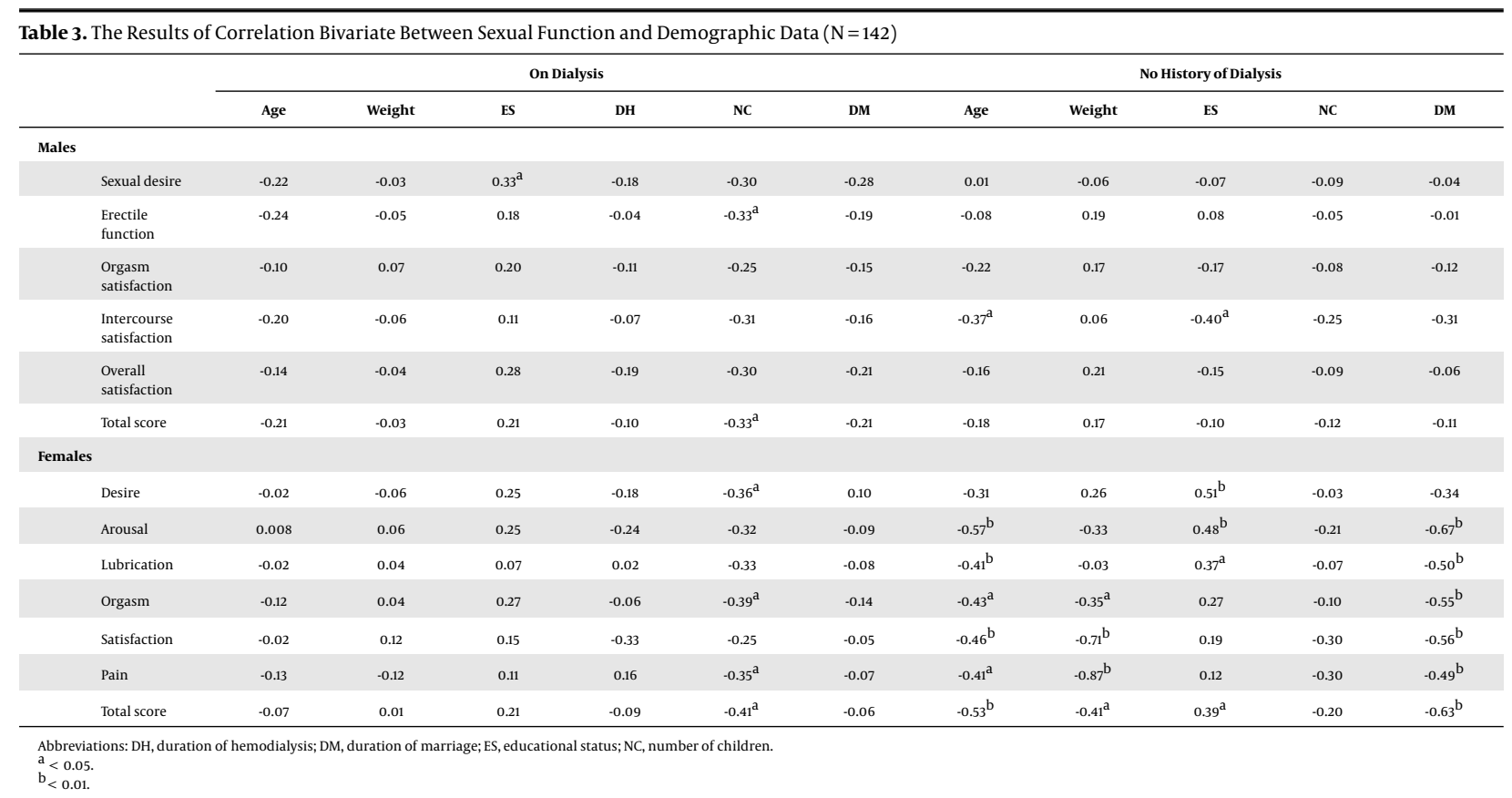

six domains was more than $80 \%$. In a global study of SD in the general population of women, the lack of desire and orgasm dysfunction were the most common sexual problems across the world, ranging from 26 to $43 \%$ and 18 to $41 \%$, respectively, which is common in the lack of desire with the current study (22). However, a systematic review in Iran reported that the prevalence of total sexual disorders was 19.2 to $77 \%$, sexual desire disorder was 15.4 to $65.8 \%$, sexual arousal disorder was 9.8 to $88.3 \%$, and lubrication disorder was 11.9 to $71.4 \%$. In addition, the reported prevalence for pain disorder was 9 to $95.9 \%$, the female orgasmic disorder was 10.5 to $76 \%$, and sexual dissatisfaction was 2.4 to $78.5 \%$. Therefore, SD in Iran has a higher rate than the global prevalence (23), and Zahedan has higher rates than other cities of Iran.

In male patients, $84.6 \%$ had erectile dysfunction that is similar to the results of Rosas et al. (33) study, which used similar tools but a higher sample size $(\mathrm{n}=302)$ and showed $82 \%$ of male patients on hemodialysis had erectile dysfunction. Turk et al. (13) found that $70 \%$ of male patients had ED. The etiology of ED includes vascular disease, hormonal dysregulation, autonomic dysfunction, medication side effects, and psychiatric disorders such as depression. Normal male sexual function is performed through the integrative response of neurologic, endocrine, vascular, and psychologic systems. Men undergoing hemodialysis can exhibit dysfunction in any of these systems (5). The increased severity of ED with increasing age agrees with the literature (14). In healthy men, 33.3\% showed various levels of SD. In other cities of Iran, the prevalence of ED was reported between 18.8 and 27\% from three studies (23), which show Zahedan has a higher prevalence of ED among the cities evaluated in Iran. However, it must be considered that different questionnaires were used in different studies.

\subsection{Limitations}

There are some limitations in this study that need to be considered for improvements in future work. First, our patient population was small because of comorbid psychiatric and medical illness. Second, despite that the study was done in one geographic area, and the rate of SD may be different in other regions, the generalization of the findings must be done with caution. Third, except for some demographic information, we did not assess the reasons for SD. Fourth, the study of sex was generally characterized by bias. Fifth, we only used self-report questionnaires for assessing sexual dysfunction without any physiologic evaluation such as photoplethysmography or duplex ultrasonography. Sixth, the current study used a cross-sectional design, and we had no idea if SD was persistent in our participants. Seventh, sexual inactivity results in lower scores on any domains of FSFI and IIEF that could cause overstimulated SD. Eighth, the role of the spouse and the quality of emotional relationship were not considered.

\subsection{Conclusions}

The findings of this study showed that the prevalence of SD was very high among men and women on hemodial- 
ysis and even in healthy females. It is important to pay attention to sexual dysfunction in the assessment and treatment plan of ESRD patients to increase their satisfaction and quality of life. Furthermore, we need to arrange psychoeducational and medical programs in the community to decrease sexual dysfunction.

\section{Acknowledgments}

This study was supported by the Zahedan University of Medical Sciences, Zahedan, Iran. The researchers appreciate the cooperation of supporters and participants.

\section{Footnotes}

Authors' Contribution: Soorgi and Shahab Lotfinia analysed Data.Nour-Mohammad Bakhshani drafted the manuscript. Shahab Lotfinia and Zohre Soorgi revised critically the manuscript.

Conflict of Interests: The authors have no conflict of interest.

Ethical Approval: The ethical approval was IR.ZAUMS.REC.1397.236.

Funding/Support: No funding or support was received.

\section{References}

1. Abouna GM. Organ shortage crisis: problems and possible solutions. Transplantation proceedings. 2008;40(1):34-8. doi: 10.1016/j.transproceed.2007.11.067.

2. Santos PR, Júnior JRFGC, Cavalcanti JU, Vieira CB, Rocha ARM, Apolônio NAM, et al. Quality of life among women with sexual dysfunction undergoing hemodialysis: a cross-sectional observational study. Health quality of life outcomes. 2012;10(1):103. doi: 10.1186/1477-7525-10-103.

3. Soykan A, Boztas H, Kutlay S, Ince E, Nergizoglu G, Dileköz AY, et al. Do sexual dysfunctions get better during dialysis? Results of a six-month prospective follow-up study from Turkey. International journal ofimpotence research. 2005;17(4):359. doi: 10.1038/sj.ijir.3901324.

4. Anantharaman P, Schmidt RJ. Sexual function in chronic kidney disease. Adv Chronic Kidney Dis. 2007;14(2):119-25. doi: 10.1053/j.ackd.2007.01.002. [PubMed: 17395114].

5. Palmer BF. Sexual dysfunction in men and women with chronic kidney disease and end-stage kidney disease. Adv Ren Replace Ther. 2003;10(1):48-60. doi: 10.1053/jarr.2003.50003. [PubMed: 12616463].

6. Kimmel PL. Psychosocial factors in adult end-stage renal disease patients treated with hemodialysis: correlates and outcomes. Am J Kidney Dis. 2000;35(4 Suppl1):S132-40. doi:10.1016/S0272-6386(00)70240X. [PubMed: 10766011].

7. Shabsigh R, Klein LT, Seidman S, Kaplan SA, Lehrhoff BJ, Ritter JS. Increased incidence of depressive symptoms in men with erectile dysfunction. Urology. 1998;52(5):848-52. doi: 10.1016/S00904295(98)00292-1. [PubMed: 9801112].

8. Heinemann J, Atallah S, Rosenbaum T. The Impact of Culture and Ethnicity on Sexuality and Sexual Function. Current Sexual Health Reports. 2016;8(3):144-50. doi:10.1007/s11930-016-0088-8.

9. Naya Y, Soh J, Ochiai A, Mizutani Y, Ushijima S, Kamoi K, et al. Significant decrease of the International Index of Erectile Function in male renal failure patients treated with hemodialysis. Int J Impot Res. 2002;14(3):172-7. doi: 10.1038/sj.ijir.3900854. [PubMed: 12058244].
10. Hyodo T, Ishida H, Masui N, Taira T, Yamamoto S, Oka M, et al. Kidney disease quality of life of Japanese dialysis patients who desire administration of sildenafil and the treatment of erectile dysfunction using sildenafil. Ther Apher Dial. 2004;8(4):340-6. doi: 10.1111/j.15260968.2004.00163.x.

11. Rosas SE, Wasserstein A, Kobrin S, Feldman HI. Preliminary observations of sildenafil treatment for erectile dysfunction in dialysis patients. Am J Kidney Dis. 2001;37(1):134-7. doi: 10.1053/ajkd.2001.20608. [PubMed: 11136178].

12. Turk S, Karalezli G, Tonbul HZ, Yildiz M, Altıntepe L, Yildiz A, et al. Erectile dysfunction and the effects of sildenafil treatment in patients on haemodialysis and continuous ambulatory peritoneal dialysis. Nephrology Dialysis Transplantation. 2001;16(9):1818-22. doi: 10.1093/ndt/16.9.1818.

13. Turk S, Guney I, Altintepe L, Tonbul Z, Yildiz A, Yeksan M. Quality of life in male hemodialysis patients. Nephron Clinical Practice. 2004;96(1):c21-7.

14. Rosas SE, Joffe M, Franklin E, Strom BL, Kotzker W, Brensinger C, et al. Prevalence and determinants of erectile dysfunction in hemodialysis patients. Kidney Int. 2001;59(6):2259-66. doi: 10.1046/j.15231755.2001.00742.x. [PubMed: 11380829].

15. Mor MK, Sevick MA, Shields AM, Green JA, Palevsky PM, Arnold RM, et al. Sexual Function, Activity, and Satisfaction among Women Receiving Maintenance Hemodialysis. Clin J Am Soc Nephrol. 2014;9(1):128-34. doi: 10.2215/CJN.05470513.

16. Dikici S, Bahadir A, Baltaci D, Ankarali H, Eroglu M, Ercan N, et al. Association of anxiety, sleepiness, and sexual dysfunction with restless legs syndrome in hemodialysis patients. Hemodial Int. 2014;18(4):80918. doi: 10.1111/hdi.12175. [PubMed: 24865547].

17. Abozead SE, Abdelrahman G, Hassan A, Ibrahim WH. Sexual Dysfunction and Health Related Quality of Life among Female Patients Undergoing Hemodialysis. American Journal of Nursing Research. 2018;6(6):547-52.

18. Finkelstein FO, Shirani S, Wuerth D, Finkelstein SH. Therapy Insight: sexual dysfunction in patients with chronic kidney disease. Nat Clin Pract Nephrol. 2007;3(4):200-7. doi: 10.1038/ncpneph0438. [PubMed: 17389889].

19. Peng YS, Chiang CK, Kao TW, Hung KY, Lu CS, Chiang SS, et al. Sexual dysfunction in female hemodialysis patients: a multicenter study. Kidney Int. 2005;68(2):760-5. doi: 10.1111/j.1523-1755.2005.00454.x. [PubMed: 16014053].

20. Yazici R, Altintepe L, Guney I, Yeksan M, Atalay H, Turk S, et al. Female sexual dysfunction in peritoneal dialysis and hemodialysis patients. Ren Fail. 2009;31(5):360-4. doi: 10.1080/08860220902883012. [PubMed: 19839835].

21. Strippoli GF, Collaborative D, Vecchio M, Palmer S, De Berardis G; Sexual Dysfunction in Hemodialysis Working Group, et al. Sexual dysfunction in women with ESRD requiring hemodialysis. Clin J Am Soc Nephrol. 2012;7(6):974-81. doi: 10.2215/CJN.12601211. [PubMed: 22490876]. [PubMed Central: PMC3362315].

22. Laumann EO, Nicolosi A, Glasser DB, Paik A, Gingell C, Moreira E, et al. Sexual problems among women and men aged 40-80 y: prevalence and correlates identified in the Global Study of Sexual Attitudes and Behaviors. Int J Impot Res. 2005;17(1):39-57. doi: 10.1038/sj.ijir.3901250. [PubMed: 15215881].

23. Nasehi AA, Raisi F, Ghaeli P, Amini M, Yahyavi ST, Arabkheradmand J, et al. Prevalence of Sexual Dysfunction Among General Population of Iran: A Systematic Review. Iranian Journal of Psychiatry and Behavioral Sciences. 2017;11(4). e7643. doi: 10.5812/ijpbs.7643.

24. Fakhri A, Pakpour AH, Burri A, Morshedi H, Zeidi IM. The Female Sexual Function Index: translation and validation of an Iranian version. J Sex Med. 2012;9(2):514-23. doi: 10.1111/j.1743-6109.2011.02553.x. [PubMed: 22146084]. 
25. Akbarzadeh M, Zeinalzadeh S, Zolghadri J, Mohagheghzadeh A, Faridi P, Sayadi M. Comparison of Elaeagnus angustifolia Extract and Sildenafil Citrate on Female Orgasmic Disorders: A Randomized Clinical Trial. J Reprod Infertil. 2014;15(4):190-8. [PubMed: 25473627]. [PubMed Central: PMC4227976].

26. Garimella PS, Paudel ML, Ensrud KE, Marshall LM, Taylor BC, Fink HA et al. Association between body size and composition and erectile dysfunction in older men: Osteoporotic Fractures in Men Study. J Am Geriatr Soc. 2013;61(1):46-54. doi: 10.1111/jgs.12073. [PubMed: 23311552] [PubMed Central: PMC4028028].

27. Pakpour AH, Zeidi IM, Yekaninejad MS, Burri A. Validation of a translated and culturally adapted Iranian version of the International Index of Erectile Function. J Sex Marital Ther. 2014;40(6):541-51. doi: 10.1080/0092623X.2013.788110. [PubMed: 24308814].

28. Berman JR, Bassuk J. Physiology and pathophysiology of female sexual function and dysfunction. World J Urol. 2002;20(2):111-8. doi: 10.1007/s00345-002-0281-4. [PubMed: 12107542].

29. Filocamo MT, Zanazzi M, Li Marzi V, Lombardi G, Del Popolo G,
Mancini G, et al. Sexual dysfunction in women during dialysis and after renal transplantation. J Sex Med. 2009;6(11):3125-31. doi: 10.1111/j.1743-6109.2009.01400.x. [PubMed:19627463].

30. Seethala S, Hess R, Bossola M, Unruh ML, Weisbord SD. Sexual function in women receiving maintenance dialysis. Hemodial Int. 2010;14(1):5560. doi: 10.1111/j.1542-4758.2009.00404.x. [PubMed: 19758295].

31. Goldstein I. Current management strategies of the postmenopausal patient with sexual health problems.J SexMed.2007;4 Suppl 3:235-53. doi: 10.1111/j.1743-6109.2007.00450.x. [PubMed: 17394596].

32. Kettas E, Cayan F, Akbay E, Kıykım A, Cayan S. Sexual dysfunction and associated risk factors in women with end-stage renal disease. The journal of sexual medicine. 2008;5(4):872-7. doi: 10.1111/j.17436109.2007.00664.x

33. Rosas SE, Joffe M, Franklin E, Strom BL, Kotzker W, Brensinger C, et al. Association of decreased quality of life and erectile dysfunction in hemodialysis patients. Kidney Int. 2003;64(1):232-8. doi:10.1046/j.15231755.2003.00042.x. [PubMed: 12787414]. 